\title{
Identification of Sex Hormone-Binding Globulin in the Human Hypothalamus
}

\author{
Zsófia Herbert $^{\mathrm{a}}$ Susanne Göthe ${ }^{\mathrm{b}}$ Jack D. Caldwell ${ }^{\mathrm{c}}$ \\ Hans-Gert Bernstein ${ }^{\mathrm{e}}$ Christian Melle ${ }^{d}$ Ferdinand von Eggeling ${ }^{d}$ \\ John Lewis ${ }^{f}$ Gustav F. Jirikowski ${ }^{a}$ \\ ${ }^{a}$ Ludwig-Maximilian-Universität München, Department of Biology 2, Munich, Germany; ${ }^{\text {b}}$ Friedrich-Schiller- \\ Universität Jena, Department of Anatomy 2, Jena, Germany; ${ }^{c}$ University of Illinois at Rockford, \\ Department of Biomedical Science, Rockford, III., USA; ${ }^{\mathrm{d}}$ Friedrich-Schiller Universität-Jena, CUCA, \\ Department of Human Genetics and Anthropology, Jena, Germany, ${ }^{e}$ Otto-von-Guericke-Universität Magdeburg, \\ Department of Psychiatry, Magdeburg, Germany, and ${ }^{\mathrm{f} C l i n i c a l ~ B i o c h e m i s t r y ~ U n i t, ~}$ \\ Canterbury Health Laboratories, Christchurch, New Zealand
}

\section{Key Words}

Steroid-binding globulin - Cerebrospinal fluid ·

Paraventricular nucleus - Arcuate nucleus - Supraoptic nucleus - Suprachiasmatic nucleus - Bed nucleus of the stria terminalis $\cdot$ Clinical neuroendocrinology

\begin{abstract}
Gonadal steroids are known to influence hypothalamic functions through both genomic and non-genomic pathways. Sex hormone-binding globulin (SHBG) may act by a non-genomic mechanism independent of classical steroid receptors. Here we describe the immunocytochemical mapping of SHBG-containing neurons and nerve fibers in the human hypothalamus and infundibulum. Mass spectrometry and Western blot analysis were also used to characterize the biochemical characteristics of SHBG in the hypothalamus and cerebrospinal fluid (CSF) of humans. SHBG-immunoreactive neurons were observed in the supraoptic nucleus, the suprachiasmatic nucleus, the bed nucleus of the stria terminalis, paraventricular nucleus, arcuate nucleus, the perifornical region and the medial preoptic area in human brains. There were SHBG-immunoreactive axons in the median eminence and the infundibulum. A partial colocalization with oxytocin could
\end{abstract}

be observed in the posterior pituitary lobe in consecutive semithin sections. We also found strong immunoreactivity for SHBG in epithelial cells of the choroid plexus and in a portion of the ependymal cells lining the third ventricle. Mass spectrometry showed that affinity-purified SHBG from the hypothalamus and choroid plexus is structurally similar to the SHBG identified in the CSF. The multiple localizations of SHBG suggest neurohypophyseal and neuroendocrine functions. The biochemical data suggest that CSF SHBG is of brain rather than blood origin.

Copyright $(2005$ S. Karger AG, Basel

\section{Introduction}

Sex hormone-binding globulin (SHBG) is a glycoprotein that has been identified in several tissues of different mammalian species. Alternate splice variants and glycosylation of SHBG have been observed in different tissues. The outcome of this is a specific molecular weight pattern of the expressed protein in the different tissues [1-4]. Our laboratory and others have reported an intrinsic expression of SHBG in the hypothalamus of rats $[5,6]$.

One model of SHBG action suggests that it is a carrier protein for steroids [7] while a more recent model suggests

\section{KARGER \\ Fax +4161306 1234 E-Mail karger@karger.ch} www.karger.com
(C) 2005 S. Karger AG, Basel 0028-3835/05/0815-0287\$22.00/0

Accessible online at: www.karger.com/nen
Zsófia Herbert

LMU-München, Institut für Biologie 2

Grosshadernerstrasse 2

DE-82152 Planegg-Martinsried (Germany)

Tel. +4989218074313, Fax +4989218074304, E-Mail telapo@gmx.de 
that SHBG may bind to a membrane receptor to induce a rapid steroid effects through a G-protein-mediated process [for review, see 8]. This receptor has been functionally identified in a number of tissues including prostate, testis, breast, liver and brain [8-12], its structural features however are still unknown. Recent findings show that SHBG-like proteins secreted from sexually dimorphic structures in the rodent lacrimal and submandibular glands may serve as pheromones [13].

Little is known about the functional importance of SHBG in the brain. It has been shown that SHBG coupled to estradiol may play a role in the stimulation of oxytocin release in the rat hypothalamus [14]. Intraventricular infusions of SHBG, with and without bound estradiol, facilitate female sexual receptivity in rats while SHBG coupled to dihydrotestosterone blocks this effect $[15,16]$, however the effects have not been tested in humans.

The aim of the present study was to assess the distribution of SHBG in the human hypothalamus, choroid plexus and infundibulum. SELDI-TOF mass spectrometry was used to characterize the SHBG molecule expressed in the hypothalamus and to compare its structure with that of serum SHBG, which is known to be expressed in liver, and with SHBG from the cerebrospinal fluid.

\section{Materials and Methods}

\section{Tissue}

Human hypothalami, both male $(\mathrm{n}=4)$ and female $(\mathrm{n}=3)$ (mean age $69 \pm 14$ years) with a mean postmortem time $<30 \mathrm{~h}$, were obtained from the Department of Pathology, FSU-Jena. Experiments were approved by the Ethics Commission, FSU Jena, protocol No. 1065-03/03.

After dissection of the retrochiasmatic portion of the hypothalami, including the mammillary bodies, tissue samples were fixed by immersion in 4\% paraformaldehyde for at least 3 weeks, dehydrated and embedded in paraffin. Small blocks containing the hypophysial stalk and the median eminence (ME) were dissected and fixed separately for 1 day in the same fixative prior to dehydration in ascending ethanol series and embedding in Epon for semithin sectioning. Unfixed samples of hypothalamus and choroid plexus $(n=3)$ were dissected and frozen at $-80^{\circ} \mathrm{C}$ for biochemical analysis. Cerebrospinal fluid (CSF) samples were obtained from a departmental collection of control samples [for details, see 17]. Serum samples were collected from 4 volunteer medical students in the laboratory. Both CSF and serum samples were stored at $-80^{\circ} \mathrm{C}$ until biochemical investigation.

\section{Immunocytochemistry}

Eight- to $10-\mu \mathrm{m}$ thick serial frontal sections were cut on a Reichert microtome and mounted on glycerol and egg albumincoated glass slides. After removal of the paraffin with xylene and rehydration, sections were washed in phosphate-buffered saline (PBS) for $2 \mathrm{~h}$ followed by treatment with $3 \% \mathrm{H}_{2} \mathrm{O}_{2}$ and $10 \%$ meth- anol in PBS for 20 min at room temperature (RT), to block endogenous peroxidase activity. After washing in PBS for $1 \mathrm{~h}, \mathrm{PBS}$ containing $2 \%$ normal goat serum was applied for $2 \mathrm{~h}$. After another washing step in PBS, sections were incubated in anti-SHBG overnight at $4^{\circ} \mathrm{C}$. We used a mouse monoclonal antibody (clone 16D5, for production and characterization see Lewis et al. [18]) at a dilution of 1:250 in PBS containing 2\% BSA (PBS-BSA). Sections were then washed in PBS and incubated in biotin-conjugated goat antimouse IgG (Vector Laboratories, 1:150 in PBS-BSA, $2 \mathrm{~h}$ at RT). After washing, streptavidin-peroxidase-complex was applied (Vector Laboratories 1:150 in PBS-BSA, $2 \mathrm{~h}$ at RT). The immunoreaction was visualized with freshly prepared $3^{\prime}, 3^{\prime}$-diaminobenzidine (DAB) and $\mathrm{H}_{2} \mathrm{O}_{2}$ in PBS (reagents were obtained from Sigma). After staining, sections were rinsed in distilled water and then dehydrated through an ascending series of ethanol and mounted in Entellan $^{\circledR}$ (Merck). Immunocytochemical controls were performed with normal goat serum instead of SHBG antibody or with antiSHBG preabsorbed with synthetic SHBG (100 ng/1 ml antiserum in the final dilution).

Serial $1-\mu \mathrm{m}$-thick semithin sections of the infundibulum and the ME were incubated in $10 \%$ sodium methoxide for $2 \mathrm{~min}$, to remove epoxy resin, prior to immersion in PBS. Consecutive sections were stained either for SHBG, as described above, or for oxytocin (OT). Rabbit antiserum to OT (Chemicon AB 911) was used at a dilution of $1: 1,000$ in PBS overnight at $4^{\circ} \mathrm{C}$. Immunoprecipitates were visualized with anti-rabbit $\operatorname{IgG} 1: 100$ for $1 \mathrm{~h}$ and rabbit PAP complex 1:100 in PBS and stained with DAB (all reagents obtained from Sigma, Munich). Stained slides were coverslipped with Entellan ${ }^{\circledR}$.

Sections were examined with an Olympus BX50 microscope equipped with a digital camera, Olympus DP10 and DP-Soft 3.0 software for microphotography. Anatomical locations of the labeled cells were determined according to the cytoarchitectonic descriptions of Mai et al. [19].

For control purposes, SHBG antibody was preincubated with the antigen before being applied to the tissue sections. To prevent the cross-reaction of the second antibodies, we omitted the antiSHBG step in a further control experiment.

\section{Purification of $S H B G$}

For mass spectrometric analysis, human hypothalamic tissues were homogenized mechanically followed by sonication in lysis buffer $\left(0.1 \mathrm{M} \mathrm{NaPH}_{4} \mathrm{pH} 7.5\right.$ containing $2 \mathrm{mM} \mathrm{MgCl}$ (Sigma), $0.5 \%$ (v/v), CHAPS (Sigma), $5 \mathrm{~m} M$ EDTA (Sigma), $0.02 \mathrm{~m} M$ PMSF (Sigma), $0.1 \mathrm{~m} M$ leupeptin (Serva), $0.04 \mu \mathrm{l} / \mathrm{ml} \beta$-mercaptoethanol (Sig$\mathrm{ma}) ; 5 \mathrm{ml} /$ hypothalamus) and centrifuged at $10,000 \mathrm{~g}$ at $3^{\circ} \mathrm{C}$ for $30 \mathrm{~min}$. CSF and the serum samples were centrifuged the same way.

SHBG was purified from the supernatant of the probes using IDM affinity beads (Chipergen Biosystems, Inc.). $10 \mu$ l protein A (Sigma) were coupled onto $5 \mu$ l of the beads. Monoclonal SHBG antibody from mouse (clone $16 \mathrm{D} 5$ ) was incubated on the protein A coupled beads overnight at $4^{\circ} \mathrm{C}$. Binding capacity of protein A beads is $10 \mathrm{mg} / \mathrm{ml} \mathrm{IgG}$ in $1 \times$ PBS. We incubated $500 \mu \mathrm{l}$ of each tissue sample with $10 \mu \mathrm{l}$ protein A-anti-SHBG beads overnight at $4^{\circ} \mathrm{C}$ in an end-over-end mixer. After washing, bound SHBG was eluted with $50 \%(\mathrm{v} / \mathrm{v})$ acetonitrile in $0.5 \%(\mathrm{v} / \mathrm{v})$ trifluoroacetic acid for mass spectrometric analysis. Alternatively, we used polyclonal anti-ABP (653 and 882) raised in rabbit diluted 1:10 in PBS to elute SHBG from the column. For details of preparation, characterization and specificity of these antibodies, see Becchis et al. [20]. 
Fig. 1. Localization of SHBG-immunoreactive structures in the human hypothalamus. A-E Diagrams of frontal hypothalamic sections from anterior to posterior $(\operatorname{arc}=$ arcuate nucleus; bnst = bed nucleus of the stria terminalis; $b$ stc $=$ central nucleus of the bed nucleus of the stria terminalis; bnst-pm = posteriomedial component of the bed nucleus of the stria terminalis; $\mathrm{CA}=$ anterior commissure; fo = perifornical region; $\mathrm{FX}=$ fornix; inf = infundibulum; pvn = paraventricular nucleus; $\mathrm{scn}=$ suprachiasmatic nucleus; son = supraoptic nucleus; rson = retrochiasmatic part of the supraoptic nucleus; $\mathrm{ME}=$ median eminence; $\mathrm{NO}=$ optic nerve; $\mathrm{TO}=$ optic tract; $\mathrm{XO}=$ optic chiasm; III = third ventricle). Asterisks represent SHBGIR cells. Circles represent immunoreactive fibers. The number of asterisks and circles indicate the relative number of the stained structures in the distinct areas. F Sagittal view of the hypothalamus for the exact localization of the frontal sections. $\mathrm{CM}=$ Mammillary bodies.
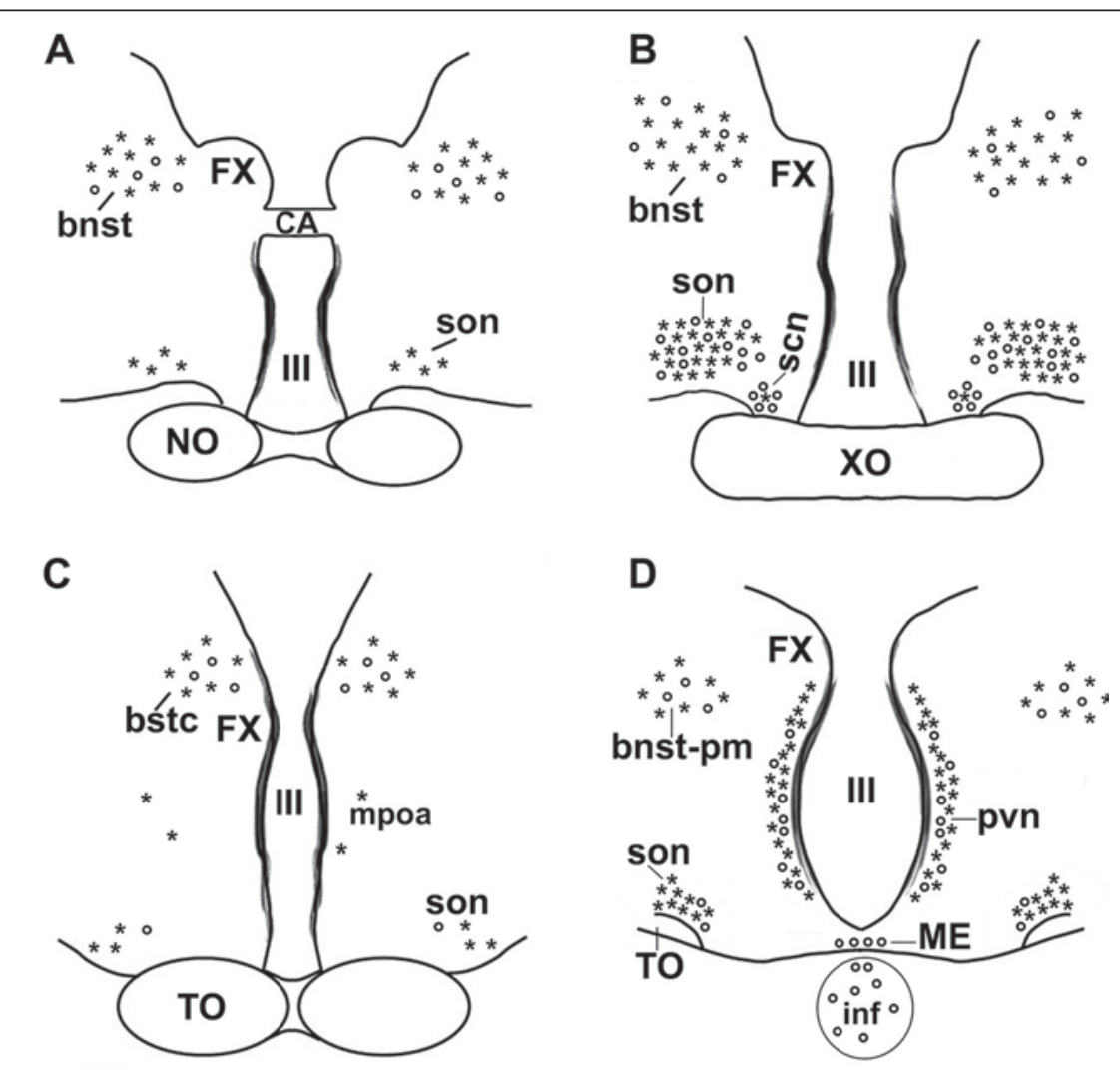

E

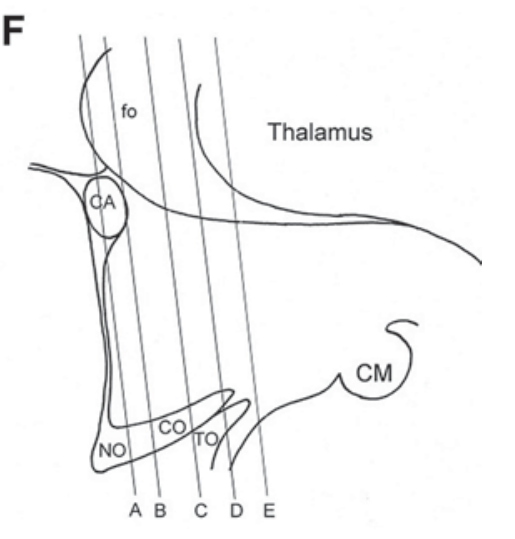

SELDI-TOF MS Analysis

Surface-enhanced laser desorption ionization-time of flight mass spectrometry (SELDI-TOF) analysis was applied to determine the mass of the bound proteins on the beads. $3 \mu 1$ of the eluted probes were dried on the hydrophobic surface of a H4 chip array after spots were washed with $27 \%(\mathrm{v} / \mathrm{v})$ acetonitrile in $0.1 \mathrm{M}$ PBS $(\mathrm{pH} 7.4)$. We used $2 \times 0.5 \mu l$ saturated sinapic acid as matrix solution. The chip arrays were analyzed in a ProteinChip Reader (PBSII; Chipergen Biosystems, Inc.) according to an automated data collection protocol [21]. The instrument was used in positive ion mode. Laser intensity was set at 300 (corresponding to approximately $200 \mu \mathrm{J}$ ), using a nitrogen laser, emitting at $337 \mathrm{~nm}$. The digitizer was operated at $250 \mathrm{MHz} .105$ transients were averaged over $66 \%$ of the target area in a linear sweep to generate each spectrum. Bovine serum albumin and chicken conalbumin were used for external calibration. A deviation exceeding $0.3 \%$ from the protein standard was considered significant. We used Chipergen ProteinChip Software 3.1 to data analysis and representation.

PBS instead of tissue extract was applied to the protein A beads coupled to anti-SHBG as a control. We also coupled anti-corticosteroid-binding globulin to the protein A beads to test for the specificity of binding of the beads complex. The eluted samples were examined in both cases with mass spectrometry as described above. 
Fig. 2. SHBG-labeled structures in the human hypothalamus. A A group of labeled magnocellular neurons in the son. B Higher magnification suggests cytoplasmic staining of SHBG in the neurons of the SON. The neuronal nuclei showed no immunoreactivity. C A population of labeled magnocellular (black arrowheads) and parvocellular (arrow) neurons in the paraventricular nucleus. In the neuropil associated with the third ventricle (III) is a specific immunostaining for SHBG. Scattered cells in the ependyma are SHBG positive (empty arrowheads). D SHBG-immunoreactive fiber network with varicosities (arrowheads) in the ME. E SHBG-labeled epithelial cells in the choroid plexus. F No immunoreactivity was detected in the case of omitted primary antibody. Photo was taken in the PVN close to the third ventricle. Scale bars: $10 \mu \mathrm{m}$ for B, D, E; $20 \mu \mathrm{m}$ for $\mathbf{A}, \mathbf{F}$, and $40 \mu \mathrm{m}$ for $\mathbf{C}$.
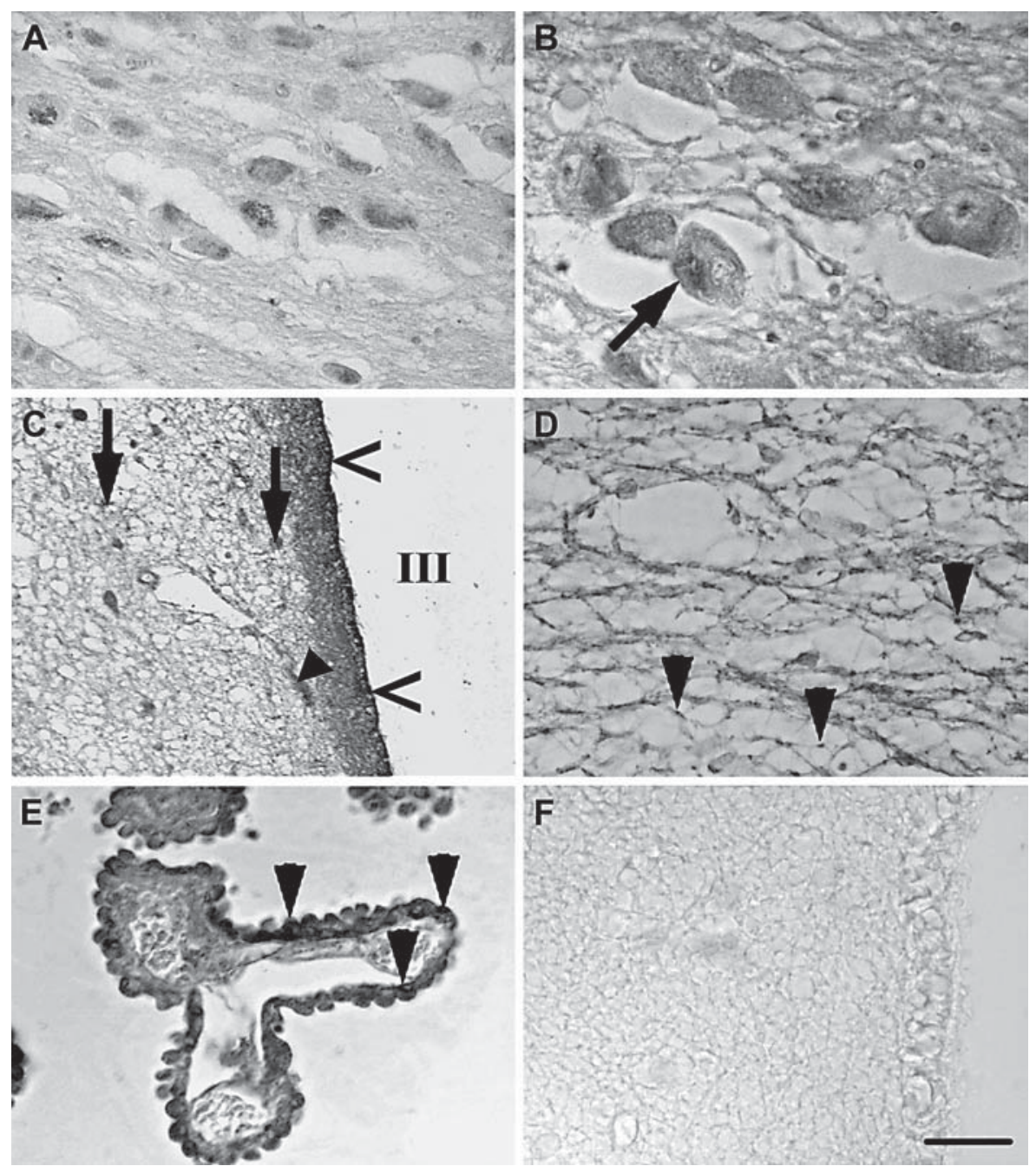

\section{Western Blot Analysis}

Further samples of eluted protein were reconstituted in $20 \mu \mathrm{l}$ SDS-gel loading buffer (Novagen, Inc.) and boiled for $5 \mathrm{~min}$. Electrophoresis was performed in $4-10 \%(10 \mathrm{v} / \mathrm{w})$ polyacrylamide gradient gel. Following SDS-PAGE, protein bands were blotted at $400 \mathrm{Vh}, 20^{\circ} \mathrm{C}$ onto PVDF membranes (Amersham) in blotting buffer $(6.35 \mathrm{~g}$ Tris base, $3.62 \mathrm{~g}$ glycine, $50 \mathrm{ml}$ methanol in $250 \mathrm{ml}$ distilled water). SHBG was visualized with the ABC method as described above. Rabbit protein-weight marker mix (Novagen) was used as molecular weight references.

\section{Results}

\section{Localization of SHBG in the Human Hypothalamus}

An overview of the hypothalamic SHBG distribution is given in figure 1 . SHBG immunoreactivity could be detected in the perikarya of neurons and ependymal cells and in nerve fibers. No labeling in the nucleus could be observed. SHBG-immunoreactive (SHBG-IR) cells and fibers could be found in the magnocellular portions of bed nucleus of the stria terminalis (bnst) (fig. 1A-D), supraoptic nucleus (son) (fig. 1A-F, fig. 2A,B), paraventricular nucleus (pvn) (fig. 1D,E, fig. 2C, arrowhead) and the perifornical region (fo) (fig. 1E). Single stained cells were found distributed in the medial preoptic area (mpoa) (fig. 1C). SHBG-IR cells were also detected rostral to the pvn in the posterior part of the hypothalamus (fig. 1E), an area that does not correspond to any previously described hypothalamic nucleus. Scattered parvocellular neurons were labeled in the arcuate nucleus (arc) (fig. 1E) and in the pvn (fig. 2C, arrows).

Several immunoreactive fibers were seen in the infundibulum (fig. 1D,E, fig. 3A). Strong arborization of stained fibers was seen in the ME (fig. 1D, fig. 2D) and in the su- 
Fig. 3. Consecutive semithin section of infundibulum immunostained for SHBG shows specific reaction product in single axonal varicosities $(\mathbf{A})$. The subsequent section reveals coexistence with OT in some of these structures (B). Different arrowheads show examples of axons immunoreactive for both OT and SHBG. Scale bar: $5 \mu \mathrm{m}$.
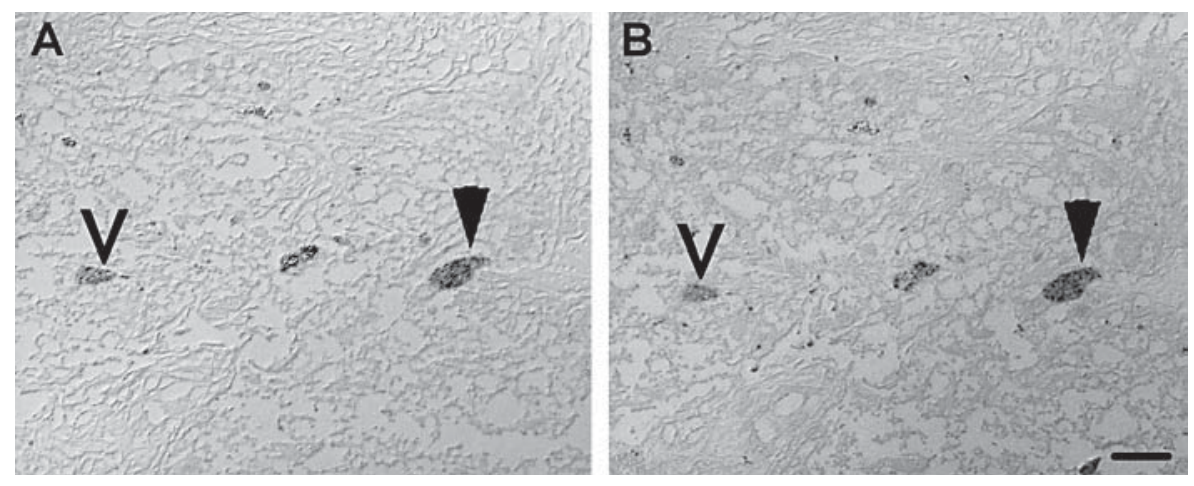

prachiasmatic nucleus (SCN), while stained perikarya were only seen in the anterior part of this nucleus (fig. 1D). SHBG-IR cells were also found in a small portion of the ependymal cells, lining the third ventricle (fig. $2 \mathrm{C}$, empty arrowheads) and in most of the epithelial cells of the choroid plexus (fig. 2E, arrowheads). Diffuse SHBGIR occurred in the neuropil surrounding the third ventricle (fig. 2C); this staining was particularly abundant in the mpoa. Immunostaining was completely absent in the immunocytochemical controls (fig. 2F), indicating that neuronal staining was specific for SHBG-IR.

In semithin sections it was possible to identify distinct axonal varicosities in the ME and the infundibulum. Examination of consecutive semithin sections revealed coexistence of SHBG (fig. 3A) with OT (fig. 3B) in identical axons.

\section{Mass Analysis of the SHBG Protein}

SELDI-TOF MS analysis identified two protein peaks with different molecular weights which were specifically bound to the monoclonal SHBG antibody (fig. 4). A $49,605 \pm 6$ Da protein peak was identified in the human hypothalamus (HT), CSF, serum and choroid plexus. A $53,909-D a$ protein was found only in the serum. The control experiments showed only a 48,367-Da protein signal, which is under-represented in the tissue probes. This peak represents an immunoglobulin heavy chain molecule originating from the eluted antibody. The second control experiment proving the specificity of the protocol showed no protein peaks.

Fig. 4. SELDI-TOF analysis of the affinity beads purified human tissue probes. PC: Plexus choroideus; HT: hypothalamus; CSF: cerebrospinal fluid; SER: serum. A 49,605 \pm 6 Da protein could be identified in all the studied tissue probes. The 53,909-Da protein

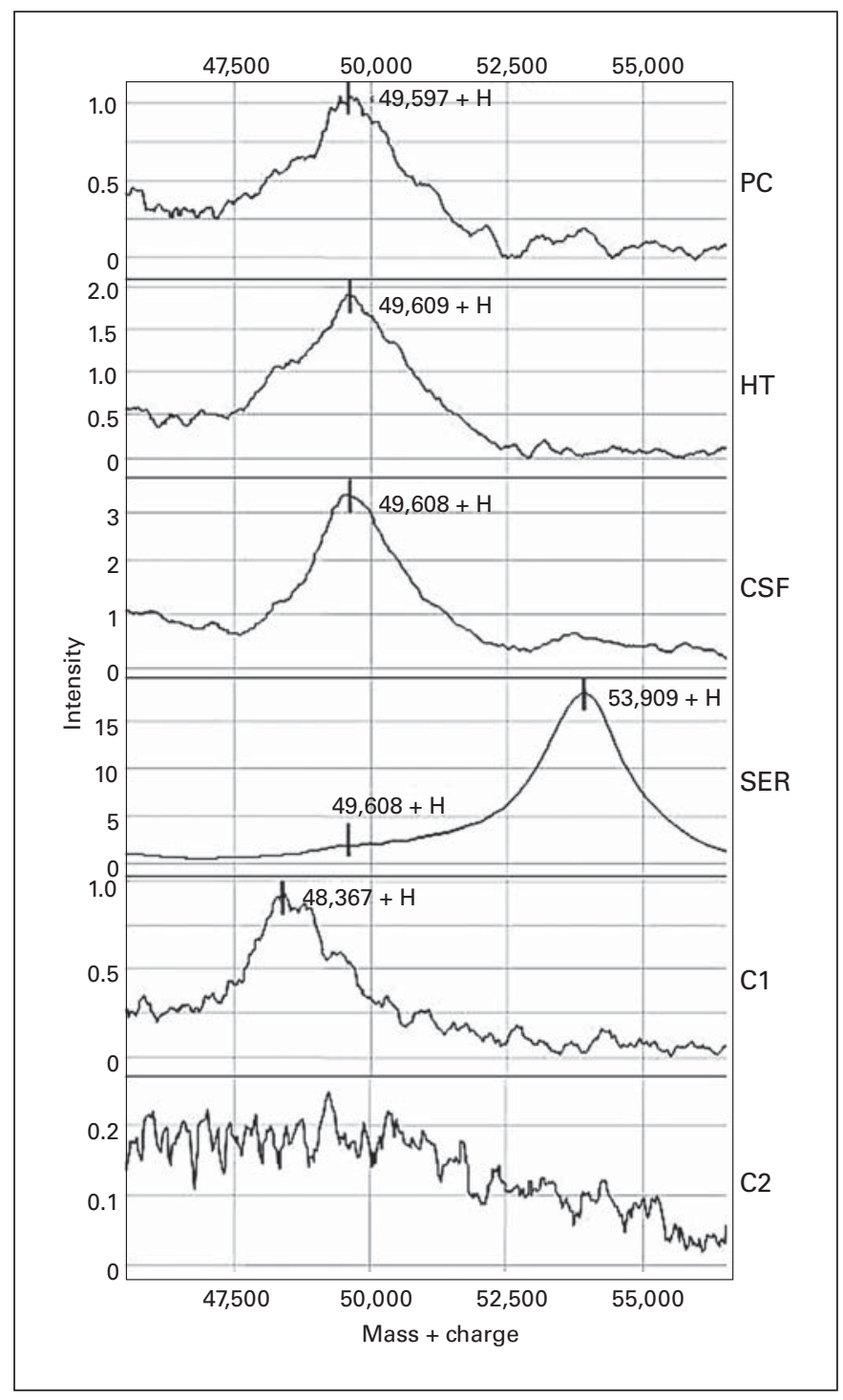

was found only in the blood plasma. C1: The first control experiment showed a 48,367-Da protein, which resembles eluted antibody. C2: Second control experiment shows spectrum of a hypothalamus sample eluted from unspecific antibody coupled beads. 


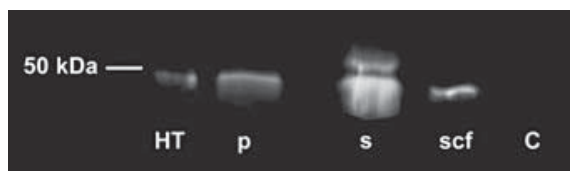

Fig. 5. Western blot analysis of the affinity beads purified human tissue probes. Blot shows proteins eluted with polyclonal SHBG antibody from the beads. Two distinct SHBG-immunoreactive proteins with different molecular weights are present in the examined tissues: a smaller one in the hypothalamus, choroid plexus, serum and in the CSF. In serum an additional larger protein was observed. HT: hypothalamus; p: plexus choroideus; scf: spinal cord fluid; s: serum; C: control; SHBG antibody.

\section{Western Blot Analysis}

Western blot analysis of the purified samples showed bands at two different molecular weights (fig. 5). A 49-kDa protein band could be found in all tissue probes, while a higher mass protein (around $53 \mathrm{kDa}$ ) was only seen in the serum sample. During this process the antibody was not detected in the mass interval presented.

\section{Discussion}

Our immunocytochemical findings describe for the first time cellular localization and distribution of SHBG in the human hypothalamus. We found that neuronal perikarya and fibers were detected in the magnocellular supraoptic nucleus, bed nucleus of the stria terminalis, paraventricular nucleus, perifornical nucleus, arcuate nucleus and in the parvocellular suprachiasmatic nucleus. SHBG-IR fibers were detected throughout the hypothalamic nuclei, in the ME and in the infundibulum. The staining of fibers in hypothalamus, ME and infundibulum indicates that SHBG is most likely subject to axonal transport to the posterior pituitary lobe. It seems possible that posterior pituitary SHBG is liberated into the systemic circulation along with OT. This is also supported by previous immunoelectron microscopical studies, which show SHBG localized in posterior pituitary secretory vesicles in the rat where it is colocalized with OT [22]. Further, evidence that SHBG in the hypothalamus shows the same characteristics as SHBG from secretory organs such as the testis and mouse lacrimal glands $[13,23]$ may indicate that it is packaged in synaptic vesicles for extracellular release.

The presence of immunoreactive SHBG in human hypothalamus suggests its involvement in human neurophysiology and possibly neuropathology. Our behavioral data in rats suggest that SHBG is important in control of reproductive behaviors $[15,16]$. The observation that estradiol levels control brain SHBG expression [24] also suggests that SHBG is involved in neuroendocrine control. Serum SHBG levels have been shown to increase in patients with Alzheimer's disease [25, 26]. Further studies need to be done to demonstrate whether changes in central SHBG exist in various neurodegenerative ailments.

The distribution of the labeled structures overlaps with the known location of hypothalamic neuropeptide OT. In semithin sections we found coexistence of OT and SHBG in neurohypophysial projections, indicating that both are packaged for transport out of the cell bodies, possibly into the posterior pituitary. We have previously demonstrated the colocalization of SHBG and OT in the rat hypothalamic nuclei and posterior pituitary [6, 27].

Our SELDI-TOF MS and Western blot studies show two SHBG molecules with different molecular weights. We confirmed evidence that there is a $53-\mathrm{kDa}$ SHBG protein in blood serum, which is known to originate from hepatocytes [28]. This 53-kDa moiety did not appear in the brain. However, a 49-kDa protein was identical in the hypothalamus and CSF that was also seen in blood serum. Alternatively, spliced and glycosylated variants of SHBG have been demonstrated in various species and in different tissues. The 49-kDa molecular weight could be identified as the SHBG variant, ABP (testosterone-estrogenbinding protein; nomenclature from Swiss-Prot Protein knowledgebase. Englebienne and Doyen [29] showed a distinct SHBG in the serum, with a molecular weight similar to the one we found. They interpreted this as originating from the testis.

We suggest that SHBG in the CSF is rather of brain origin than from blood. A portion of the hypothalamic neuroendocrine cells in humans is likely to express SHBG. Wang et al. [5] demonstrated SHBG production in rat brain using Northern blots while we used RT-PCR to identify production of SHBG in the rat brain [24]. Therefore, it is likely that the SHBG immunoreactivity identified in this study in humans is also produced in the brain.

SHBG, liberated from liquor contacting neurons [30] in the PVN, may enter the CSF, which would account for the observed diffuse immunostaining of the periventricular neuropil. Staining of ependymal and plexus epithelial cells could be due to expression or uptake of the steroidbinding globulin by those cells. It is known that ependymal cells are connected by gap junctions to the periventricular neurons, thus allowing proteins from CSF to enter the surrounding neuropil. 
The CSF is known to contain significant levels of SHBG [31], which shows alteration at different physiological and pathological stages such as in Alzheimer's disease [26].

The extensive distribution of both SHBG-IR neurons and processes suggests multiple functional properties. SHBG may be synthesized and released into blood along with the neurohypophysial hormones. Intrahypothalamic SHBG may be released within the brain where it com- bines with neurosteroids to control the modulation of mood and behavior.

\section{Acknowledgment}

Supported by IZKF, FSU-Jena, Project 1.2 to G. Jirikowski; NBL-2 to H.G. Bernstein; LUBOM Thüringen Award to Z. Herbert, and MH069810 (J.D.C.).

\section{References}

1 Joseph DR, Sullivan PM, Wang YM, Millhorn DE, Bayliss DM: Complex structure and regulation of the ABP/SHBG gene. J Steroid Biochem Mol Biol 1991;40:771-775.

2 Hammond GL, Bocchinfuso WP: Sex hormone-binding globulin: gene organization and structure/function analyses. Horm Res 1996; 45:197-201

3 Reventos J, Sullivan PM, Joseph DR, Gordon JW: Tissue-specific expression of the rat androgen-binding protein/sex hormone-binding globulin gene in transgenic mice. Mol Cell Endocrinol 1993;96:69-73.

4 Selva DM, Hogeveen KN, Seguchi K, Tekpetey F, Hammond GL: A human sex hormone-binding globulin isoform accumulates in the acrosome during spermatogenesis. J Biol Chem 2002;277:45291-45298.

5 Wang YM, Bayliss DA, Millhorn DE, Petrusz P, Joseph DR: The androgen-binding protein gene is expressed in male and female rat brain. Endocrinology 1990;127:3124-3130.

6 Herbert Z, Jirikowski GF, Petrusz P, Englöf I, Caldwell JD: Distribution of androgen-binding protein in the rat hypothalamo-neurohypophyseal system, co-localization with oxytocin. Brain Res 2003;992:151-158.

7 Pardridge WM: Transport of protein-bound hormones into tissues in vivo. Endocr Rev 1981;2:103-123.

8 Forunati N: Sex hormone-binding globulin: Not only a transport protein. What news is around the corner? J Endocrinol Invest 1999; 22:223-234.

9 Rosner W, Hryb DJ, Khan MS, Nakhla AM, Romas MA: Sex hormone-binding globulin: anatomy and physiology of a new regulatory system. J Steroid Biochem Mol Biol 1991;40: 813-820.

10 Caldwell JD: Evidence of sex hormone binding globulin binding sites in the medial preoptic area and hypothalamus. Horm Metab Res 2001;33:7-9.

11 Krupenko SA, Krupenko NI, Danzo BJ: Interaction of sex hormone-binding globulin with plasma membranes from the rat epididymis and other tissues. J Steroid Biochem Mol Biol 1994;51:115-124.
12 Hryb DJ, Kahn MS, Rosner W: Testosteroneestradiol-binding globulin binds to human prostatic cell membranes. Biochem Biophys Res Commun 1985;128:432-440.

13 Remington SG, Nelson JD: Secretoglobins: Sexually dimorphic expression of androgenbinding protein mRNA in mouse lacrimal glands. Invest Ophthalmol Vis Sci 2005;46: 31-38.

14 Caldwell JD, Song Y, Englöf I, Höfle S, Key M, Morris M: 5a-Reduced androgens block estradiol-BSA-stimulated release of oxytocin. Brain Res 2003;976:259-261.

15 Caldwell JD, Moe BD: Conjugated estradiol increases female sexual receptivity in response to oxytocin infused into the medial preoptic area and medial basal hypothalamus. Horm Behav 2000;35:38-46.

16 Caldwell JD: A sexual arousability model involving steroid effects at the plasma membrane. Neurosci Biobehav Rev 2002;26:1330.

17 Bonelli RM, Aschoff A, Niederwieser G, Heuberger C, Jirikowski GF: Cerebrospinal fluid tissue transglutaminase as a biochemical marker for Alzheimer's disease. Neurobiol Dis 2002;11:106-110.

18 Lewis JG, Longley NJ, Elder PA: Monoclonal antibodies to human sex hormone-binding globulin (SHBG): characterization and use in a simple enzyme-linked immunosorbent assay of SHBG in plasma. Steroids 1999;64:259265.

19 Mai JK, Assheuer J, Paxinos G: Atlas of the Human Brain. San Diego, Academic Press, 1997.

20 Becchis M, Sullivan PM, Ordronneau P, Petrusz P, Joseph DR: Distribution of immunoreactive androgen-binding protein/sex hormone-binding globulin in tissues of the fetal rat. Steroids 1996;61:392-400.

21 Melle C, Ernst G, Schimmel B, Bleul A, Koscielny S, Wiesner A, Bogumil R, Möller U, Osterloh D, Halbhuber KJ, von Eggeling F: Biomarker discovery and identification in laser microdissected head and neck squamous cell carcinoma with ProteinChip technology, twodimensional gel electrophoresis, tandem mass spectrometry, and immunohistochemistry. Mol Cell Proteomics 2003;2:443-452.
22 Herbert Z, Pollak E, Caldwel JD, Jirikowski GF: Subcellular localization of sex-hormone binding globulin/ SHBG in rat hypothalamus and pituitary. Society for Neuroscience Meeting, New Orleans 2003.

23 Feldman M, Lea OA, Petrusz P, Tres LL, Kierszenbaum AL, French FS: Androgen-binding protein. Purification from rat epididymis, characterization, and immunocytochemical localization. J Biol Chem 1981;256:51705175.

24 Gao G, Herbert Z, Kong J, Gabrielson N, Mautz A, Wu D, Jirikowski GF, Caldwell JD: Estradiol control of expression and levels of estradiol-binding proteins in the medial preoptic area, medial hypothalamus and pituitary. Neuroendocrinology 2003;78:61-71.

25 Paoletti AM, Congia S, Lello S, Tedde D, Orru M, Pistis M, Pilloni M, Zedda P, Loddo A, Melis GB: Low androgenization index in elderly women and elderly men with Alzheimer's disease. Neurology 2004;62:301-303.

26 Hoskins EK, Tang MX, Manly JJ, Mayeux R: Elevated sex-hormone binding globulin in elderly women with Alzheimer's disease. Neurobiol Aging 2004;25:141-147.

27 Jirikowski GF, Herbert Z, Petrusz P, Sendemir E, Caldwell JD: Co-expression of vasopressin and androgen-binding protein in the rat hypothalamus. J Chem Neuroanat 2005;29:233237.

28 Khan MS, Knowles BB, Aden DP, Rosner W: Secretion of testosterone-estradiol-binding globulin by a human hepatoma-derived cell line. J Clin Endocrinol Metab 1981;53:448449.

29 Englebienne P, Doyen G: Further evidence for distinction between sex hormone-binding globulin and an androgen-binding protein in hydatidiform mole serum. J Steroid Biochem 1983;18:649-653.

30 Vigh Teichmann I, Vigh B: The infundibular cerebrospinal-fluid contacting neurons. Adv Anat Embryol Cell Biol 1974;50:1-91.

31 Fassler R, Schwarz S, Pohl P: Demonstration of sex hormone binding globulin in human cerebrospinal fluid. Clin Endocrinol (Oxf) 1985; 23:349-359. 